\title{
ANALYSIS OF DIFFERENCES IN 3D BUILDING INFORMATION MODELING
}

\author{
J. Suziedelyte Visockiene ${ }^{1, *}$, E. Tumeliene ${ }^{1}$ \\ ${ }^{1}$ VGTU, Environmental Engineering Faculty, Department of Geodesy and Cadastre, Sauletekio av. 11, Vilnius, Lithuania-10223 - \\ Jurate.suziedelyte-visockiene@vgtu.lt; egle.tumeliene@vgtu.lt
}

KEY WORDS: Building Information Modelling, Surveyors, Architects, 3D model, Virtual reality

\begin{abstract}
The implementation of Building Information Modelling (BIM) in each project, which is planned, have a design and construction stages. In the construction stage the objects are modelled by architects, engineers, and surveyors. Modelling process allowed to construct a BIM, which replaces two-dimensional (2D) building information into a three-dimensional (3D). Noticed that 3D BIM created by surveyors is not the same as 3D BIM, which is created by architects. Therefore, the purpose of this study is to identify the differences of the created 2D draftings made by 3D models between surveyors and architect's. The surveyors make their model by using Unnamed Aerial Vehicle (UAV) system: Airborne Drone Data and Data photogrammetric processing technology. The 3D models accuracy is assessed by UAV images processing. The 3D information should be used to calculate façade geometry, volume, distances, contours, which are in the shadowed side of the house, and create 2D façade draftings. Traditionally, architects used 2D building's façade draftings for pre-design in Construction Projects (CP). 3D architectural model is created by using structural 2D draftings created with Autodesk software. The architectural 3D model is more convenient for the general design and the visual view, it is easily to evaluate the impact of the changes that will be made. The 3D architectural model helps to finish a project at a low cost and also to evaluate the effect of the changes made. The 3D model from surveys measurements shows real view of an object (with deformations), meanwhile the 3D model from architects is a corrected image. Discrepancies between surveyors and architect's 2D models made by 3D virtual reality (VR) are analysed in this article.
\end{abstract}

\section{INTRODUCTION}

BIM technology is integrated into all stages of production and life support of buildings: data collection, design work, construction, equipment, operation, repair work and demolition. That is, all the necessary information is located in the computer models: architectural, construction, technological, economic, etc. (Milyutina, 2018). The buildings are developed like the VR model by digital technology. VR incorporates 3D technologies that give a real-life and real-time illusion (Onyesolu, Eze, 2011; Mazuryk, Gervautz, 1999). VR, sometimes called Virtual Environments (VE) has drawn much attention in the last few years (Mazuryk, Gervautz, 1999; Schnabel, 2004). There are two components - the hardware and the software for building and experiencing VR and they can be harmonizing. The software components are divided into four sub-components: 3D modelling software, 2D graphics software, digital sound editing software and VR simulation software (Onyesolu, Eze, 2011). The software components require very expensive hardware. Nowadays, surveyors and architects have possibility used the virtual "GeoCloud" platform. It is remote access to geospatial software's on a pay-per-use basis (www.geocloud.work). The platform offers a processing power according to operator requests. Currently using the VR technology have to work with new or old reconstructed buildings. This processes includes a different specialist: architects, engineers, and surveyors who used the various commercial or open sources software's. The surveyor's make 3D VR model by using Unnamed Aerial Vehicle (UAV) system: Airborne Drone Data and Data photogrammetric processing technology by special photogrammetric software or Terrestrial Laser Scanner (TLS) technology. Also using Total Station (TS) and Global Navigation Satellite System (GNSS) for geo-referencing and topography measurement of object area. A 3D model, which relies on an accurate metric survey, could provide a useful base on which other analyses can be carried out, especially in the cultural heritage domain where highly detailed information that is connected to models and descriptive model data that provide a more general view of the studied (Chiabrando et al., 2019). The model from surveys measurements have real geometry with all deformations.

3D architectural new object model is created in modelling or graphical software's using non-standard native formats, and each products uses different techniques for capturing a model shape information via designer-specified parameters, storing geometry and other properties attached to geometry, and rendering the model on the computer screen. Each software products methods of doing this uses different, and very complex mathematical techniques (Lee, 1999; Smith, 2009). Therefore, 3D modelling of old buildings requires combination of surveyors measurements and architects reconstruction works. The architects having 3D models or 2D drafting from measurements make a correction. Sometimes it is problematic, because disappear important elements of object deformation and increased the volume of the reconstruction works and costs. Deformations are corrected mathematically or by architect.

The aim of this study is to identify changes between surveyors and architect's 2D drafting's made by 3D VR according to a specific example.

\section{MATERIALS}

\subsection{Testing area}

Test building is located in the Klaipeda city which is a city on the Baltic Sea coast. It is the third largest city in Lithuania (Figure 1).

Klaipeda's Old Town is notable among other towns in Lithuania for its abundance of German and Scandinavian architecture. It is unique with its fachwerk architectural style and the planned

\footnotetext{
* Corresponding author
} 
street structure, which is uncharacteristic to any other old town in Lithuania (https://en.wikipedia.org/wiki/Klaip7da ).

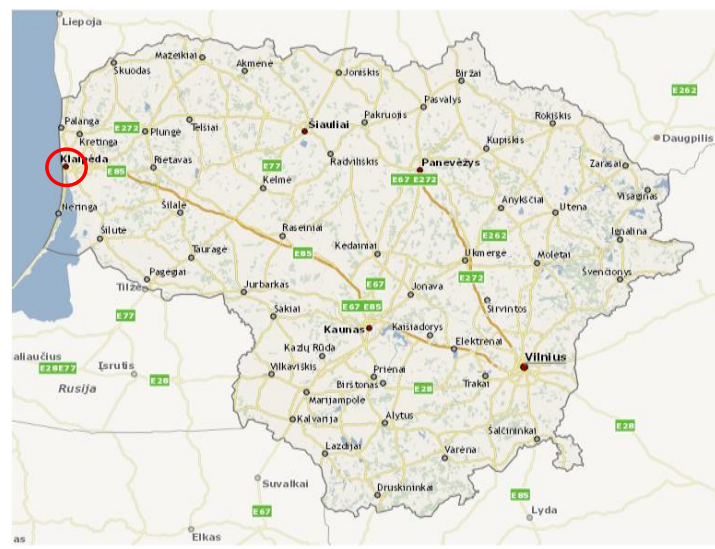

Figure 1. Location of study area (source: www.maps.lt)

Many buildings of Klaipeda's Old Town are included into the list of cultural values of real estate, therefore their handling and reconstruction works require photogrammetric measurements. The building selected for analysis is Luise sanatorium building complex (Pamario street 4), which was built in 1910. One building of the complex is sanatorium building - compact, two floors with an attic (http://www.biblioteka.lt/paveldas) (Fig. 2).

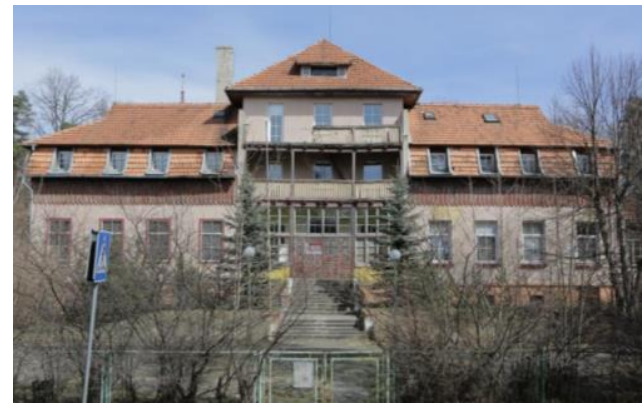

Figure 2. Western façade view of Luise sanatorium building (source: http://www.biblioteka.lt/paveldas )

The photo (Fig. 2) shows that the building is ruptured, collapsed and requires urgent reconstruction. The building's 3D model was done using photogrammetric method. 2D drafting of the facades were drawn using architect's reconstructions plans.

\subsection{Data acquisition}

The photogrammetric 3D modelling process makes from 2D images by an automated software. There are several software programs for the creation of $3 \mathrm{D}$ models using images. The workflow is generally the same for all, but there are features that make them distinct from each other. The scientist distinguished phases of the workflow (Tapio and Lahti, 2018; Verma and Bourke, 2019):

1) loading the image set. Depending on the amount of images and their resolution, this phase usually takes from a few seconds to some minutes. Images may include Global Positioning System (GPS) information.

2) aligning the images. It is to calculate the position and orientation of the camera at the moment when the image was shot.
3) the calculation of a sparse point cloud by a trigonometric (a bundle adjustment) algorithm using the tie and control points, camera locations and the lens data.

There are three photogrammetric work stages (Fig. 3): planning, field procedures, and data processing.

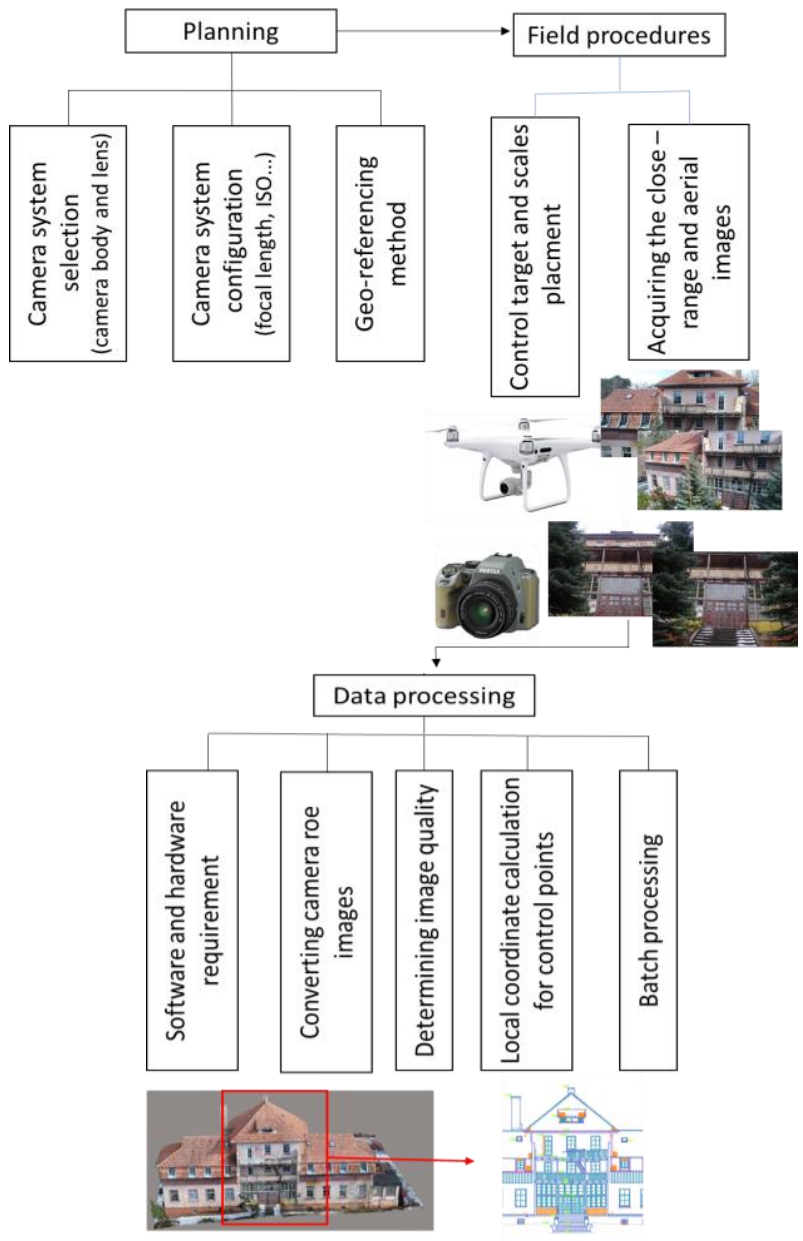

Figure 3. A schematic diagram of the photogrammetric work stages

The experimental building was shouted by Pentax K-S2 digital camera from the ground and UAV system Airborne Drone - DJI - 4 from the aerial. Like a schematic diagram (Fig. 3) the georeferencing was done by tacheometer measurement of control points fixted on the building fasades (Fig. 4).

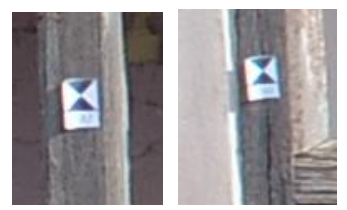

Figure 4. Example of the control points

Images processing done by ContextCapture (Bentley) software. It is a part of high quality software product family for civil engineering and urban infrastructure design (Tapio and Lahti, 2018). The software used for photogrammetric 3D modeling, which calculates the 3D point cloud very quickly. The examples of photogrammetric 3D models were shown in the figure 5 . 

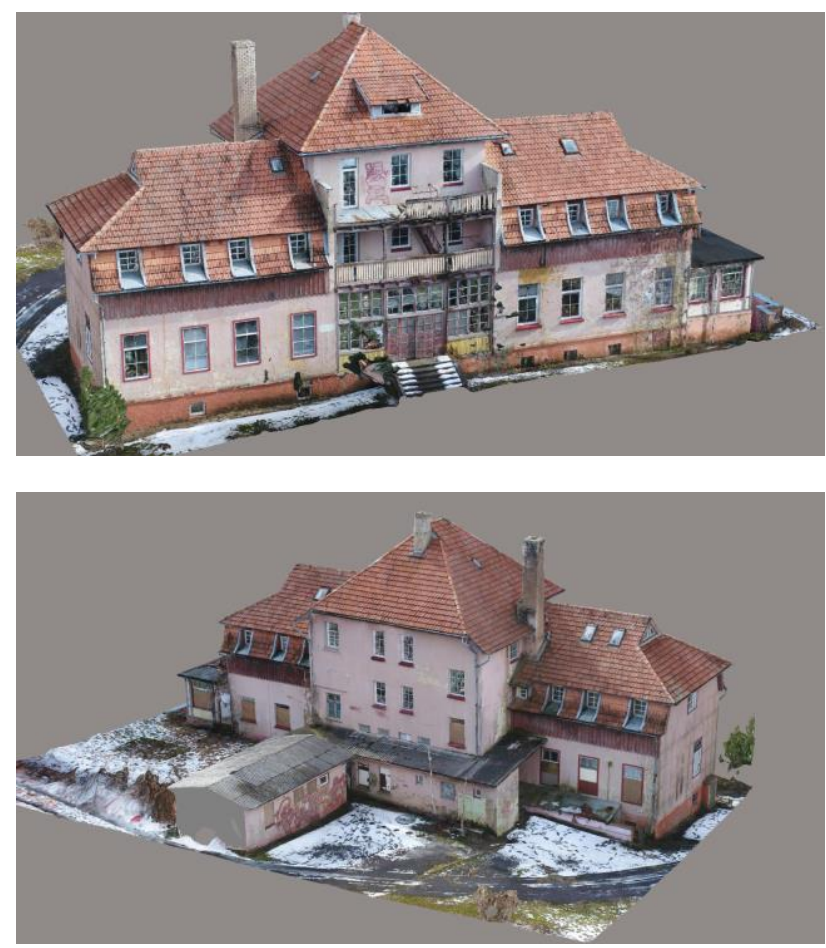

Figure 5. 3D models from surveyers measurements

In the data processing work stage 3D images are created, which are used to generate orthophoto images of all facades. This images were used for 2D drafting creation for architectural purposes (Fig. 6-9 (a)). The architects, as mentioned in the article, prepares building reconstruction 2D draftings (Fig. 6-9 (b)). Changes, which occured in surveyers 2D drafting after the architect's work are analysed in this article.

Deviations of Western façade elements are submitted in the Table 1.

Table 1. Results of deviations

\begin{tabular}{|l|l|}
\hline Elements & Deviations, cm \\
\hline Columns of stairs (Fig. 6 (a)-1) & 11 \\
\hline Height of chimney (Fig. 6 (a)-2) & $7-12$ \\
\hline Height of roof (Fig. 6 (a)-2) & 24 \\
\hline Side of roof (Fig. 6 (a)-2) & 23 \\
\hline Window of attic (Fig. 6 (a)-3) & 20 \\
\hline Balcony (Fig. 6 (a)-4) & Scratched newly \\
\hline Doors structure (Fig. 6 (a)-5) & Changed \\
\hline Treads of stairs (Fig. 6 (a)-6) & $2-10$ \\
\hline
\end{tabular}

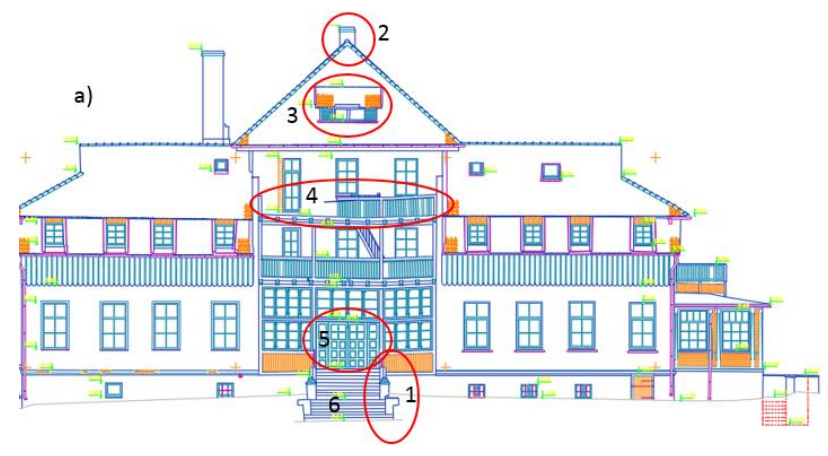

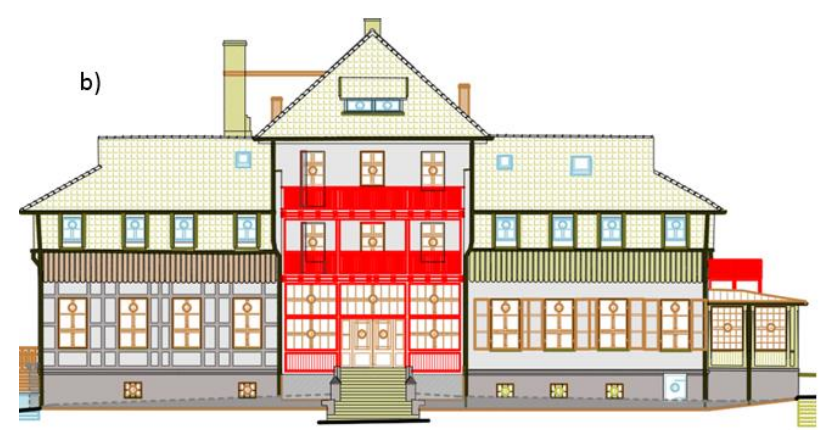

c)
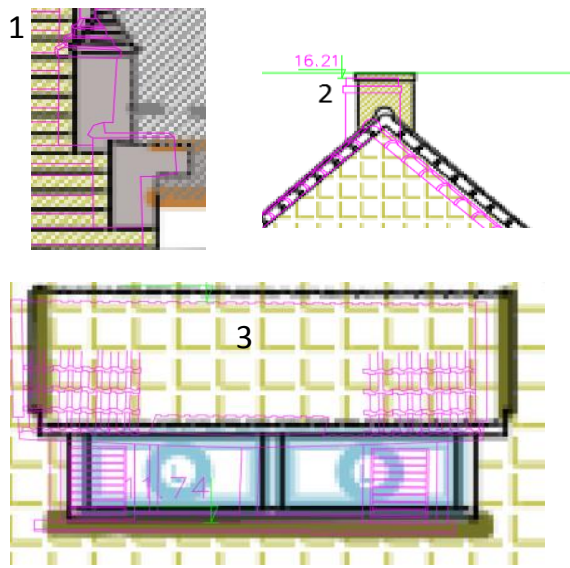

Figure 6. Western façade of the building: a) surveyors 2D model; b) architects 2D model; c) deviations between two models: 1) columns and treads of stairs; 2) chimney and roof; 3) windows of attic.

Elements in the Northern façade of the building (red square, Fig. 7 (a), (b)): stairs, doors, facade surfaces are not marked in the photogrammetric model (Fig. 7 (b)). These elements according to historical documents and photos are loaded into the reconstruction plan.
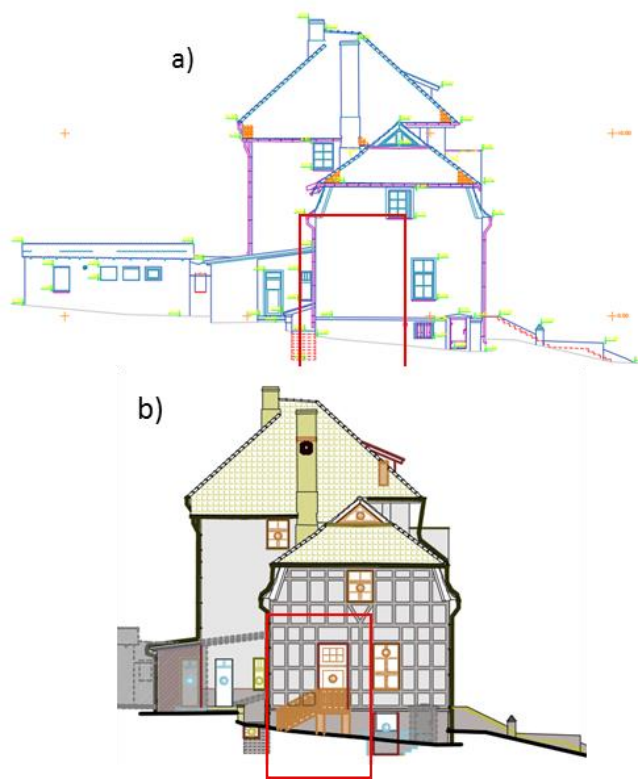

Figure 7. Northern façade of the building: a) surveyors 2D drafting; b) architects 2D drafting. 
Place in Eastern façade of the building (red square, Fig. 8 (a)) was not photographed whent photogrammetric works was performed, therefore information is missing in $3 \mathrm{D}$ and $2 \mathrm{D}$ drafting (reconstruction plan) (Fig. 8 (a)). New elements (windows, doors) using the archival or design material were scratched in to architectural drafting (Fig. 8 (b)).
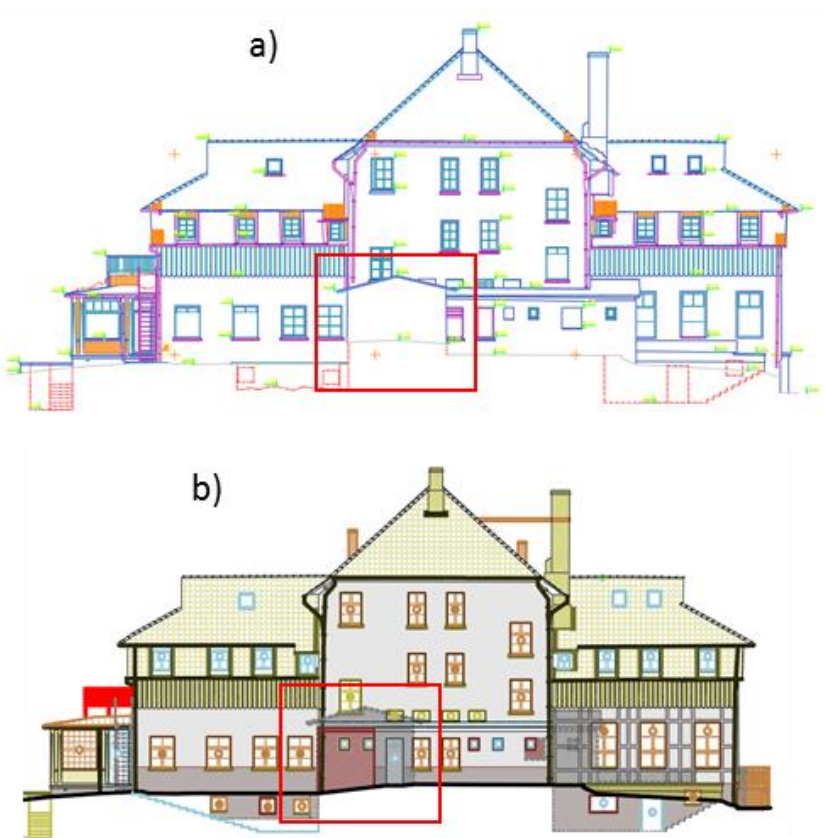

Figure 8. Eastern façade of the building a) surveyors 2D drafting; b) architects $2 \mathrm{D}$ drafting.

In Southern part of the façade in the reconstruction plan (Fig. 9 (b)) three items are marked: chimney (1), attic (2) and the windows of first floor (3). These elements are not marked in 2D drafting and 3D model which are made by surveyors (Fig. 9 (a)). The attic's windows and the first floor windows are split different (Fig. 9 (a) ir (b)). Sizes of elements changes were not measured.

a)

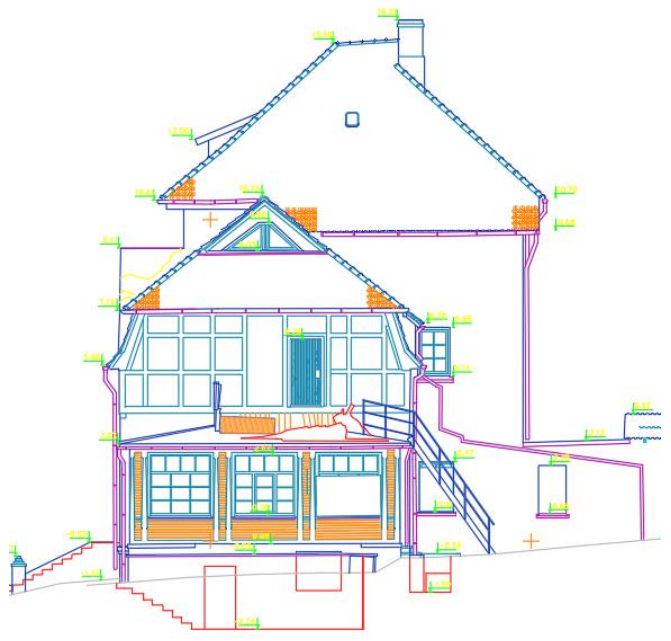

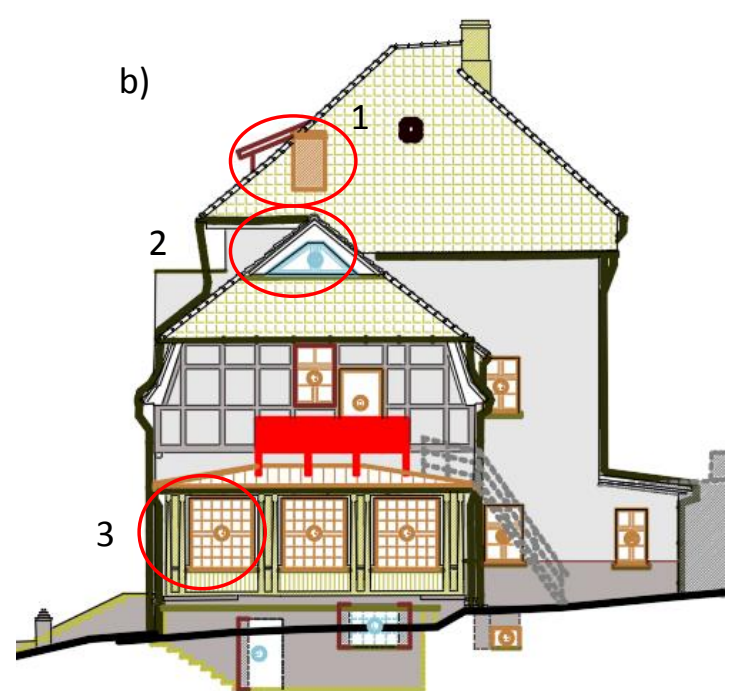

Figure 9. Southern façade of the building: a) surveys 2D drafting; b) architects 2D drafting.

The essential purpose of the reconstruction works project decisions is preserving the authenticity and valuable properties of the heritage object and integrating it into BIM technologies. The work done has to:

- improve the physical state of cultural values

- to highlight the cultural value of the heritage object;

- be based on historical, archaeological, architectural, engineering, technological and other research on the object;

- be based on scientific and technical achievements, history and new technologies, the use of which in this field must be checked.

Surveyors and architects must carry out their work responsibly, especially when it comes to heritage objects. Many new buildings will become historic after many years and will reflect the work of our time.

\section{ACKNOWLEDGEMENTS (OPTIONAL)}

We are grateful to private Lithuania company "CAD \& F ProjektServisas" for the provided data which helped accomplish our research ( http://cadf.lt/apie).

\section{CONCLUTIONS}

In this research, we used 2D drafting made by surveyors from the 3D model of the heritage object. This result quality corresponds to the accuracy of the triangulation process of images processing. The points cloud transformation was based on the geodetic reference points. The surveyors guarantee that 2D drafting results, which are giving to architects, conform the required level of detail and accuracy. Later on the responsibility for the reconstruction plan is shifted on to the architect. Therefore, when reconstructing objects of cultural heritage, close cooperation between all professionals who have to deal with the same object is necessary.

The research has shown that the deviations between facade elements after the preparation of the architect's management plan are from 2 to $24 \mathrm{~cm}$. The size of the deviations depends on how the reconstruction of the building will be carried out and if 
the element will only be tidied up or completely rebuilt using to the building management technologies. The price of the work depends on it too.

The object's research work is carried out and historical material is collected before the design of the object reconstruction. Occasionally new features can be detected during the reconstruction, which means that reconstruction works has to be stopped. New facade elements (stairs, chimney, doors) was scratched by architect (according to historical research results of the object) that were not found in the $3 \mathrm{D}$ and $2 \mathrm{D}$ surveyors results.

There has to be an obtained consent from the institution that is responsible for the protection of the cultural heritage object so there would not be any negative impact done. Department of Cultural Heritage under the Ministry of Culture controls all ongoing works in Lithuania.

\section{REFERENCES}

Chiabrando, F., Sammartano, G., Spanò, A., Spreafico, A., 2019. Hybrid 3D Models: When Geomatics Innovations Meet Extensive Built Heritage Complexes. ISPRS International Journal of Geo-Information, 8 (124). doi:10.3390/ijgi8030124.

Lee, K., 1999. Principles of CAD/CAM/CAE systems. Reading, MA: Addison, Wesley.

Mazuryk, T., Gervautz, M.,1999. Virtual Reality - History, Applications, Technology and Future. Virtual Reality.

Milyutina, M. A., 2018. Introduction of Building Information Modeling (BIM) Technologies in Construction. Journal of Physics: Conference Series 1015(4), 042038. doi :10.1088/1742-6596/1015/4/042038.

Onyesolu, M. O., Eze, F. U., 2011. Understanding Virtual Reality Technology: Advances and Applications. In book: Advances in Computer Science and Engineering, chapter 4.

Schnabel, M. A., 2004. Architectural design in Virtual Environments. A thesis at the university of Hong Kong: https://cumincad.architexturez.net/system/files/pdf/2ccd.content $.01425 . \mathrm{pdf}$

Smith, M., 2009. Curating Architectural 3D CAD Models. The International Journal of Digital Curation, 1(4), 1746-8256.

Tapio, H., Lahti, M., 2018. Photogrammetric 3D Modeling for Virtual Reality. Technical Report.

Verma, A. K., Bourke, M. C., 2019. A method based on structure-from-motion photogrammetry to generate submillimetre-resolution digital elevation models for investigating rock breakdown features. Earth Surf. Dynam., 7, 45-66, https://doi.org/10.5194/esurf-7-45-2019. 